\title{
International Journal of Pharmaceutical Investigation: Now Published with EManuscript
}

\author{
Mohammed Yunus \\ Managing Editor, International Journal of Pharmaceutical Investigation, \#9, Vinnse Towers, Wheeler Road Extension, St. Thomas Town, Bangalore, INDIA. \\ DOI: $10.5330 /$ ijpi.2019.1.1
}

The year 2019 is another milestone for International Journal of Pharmaceutical Investigation (JPHI) as it is entering to $9^{\text {th }}$ year. It is known as one of the peer-reviewed pharmaceutical journal and I am pleased to present you this issue being published by EManuscript, Bangalore, India. JPHI is publishing scholarly reviews and research articles in the field of pharmacy and bioallied Sciences. Over the years the journal is indexed with Emerging Sources Citation Index, Web of Science and Index Copernicus. The past and current issue content is available in http://jpionline.phcog.interactivedns.com/index.php/ijpi/issue/archive.

\section{Editorial policy}

JPHI Publication Ethics and Publication Malpractice Statement are based, in large part, on the guidelines and standards developed by the Committee on Publication Ethics (COPE). Manuscripts being submitted to JPHI will be preferred in IMRAD style and its mandatory to provide contributors details and author have to declare the conflict of interest. The clinical and pre-clinical experiment should be prepared accordance to "CONSORT" and "ARIVE" guidelines respectively. The manuscripts which are describing clinical findings have to provide "CONSORT" flow chart.

The manuscript published by JPHI is an open access article distributed under the terms of the Creative Commons Attribution: NoncommercialShare Alike 4.0 License, which allows others to remix, tweak and build upon the work non-commercially, as long as the author is credited and the new creations are licensed under the identical terms.

\section{Code of conduct}

The authors' submission will be handled by the section editor(s) or by the editor-in-chief. The submissions will be checked for plagiarism and send to minimum two external reviewers for their opinion. Based on their comments the authors will be communicated with acceptance message or revision request or rejection message. All the external review process will be double blind review and all the parties involved in the review process have to submit their comments within stipulated time period. Our team will provide the professional service to authors regrading formatting and pagination. Also, we will handle our authors in respectful manner and all the correspondence will be made through only corresponding author of the manuscript. The responsibilities of the corresponding author are to inform all the correspondence to the co-authors and maintain the integrity of the academic records. The submissions will be accessed by editors/ editorial board members and by the reviewers and the final decision will be provided 30-45 days after initial submission.

\section{Article processing charges}

JPHI have pre-press charges to cover the production cost with the publisher. Indian authors are required to pay Pre-Press Charges of 6500 INR (Inclusive of 18\% GST) and foreign/Overseas Indian authors are required to pay 300 USD (Pre-Press Charges) upon acceptance. The above charges are applicable to accepted articles only. JPHI will not have any charges for submission or peer review of the submitted manuscripts.

\section{Call for editorial board members and reviewers}

We are seeking active scholarly active academic members/ researcher to support or act as a mentor in the growth of JPHI. Editorial board members will have to screen submitted papers and help us continue to meet our mission; we are looking to add new members to our Editorial Board to serve initial two/ three-year terms. As an Editorial Board Member, you will be expected to perform the following responsibilities:

- $\quad$ Review 2-3 new papers per quarter.

- Participate in internal quality improvement activities.

- Communicate with editors in a timely and professional manner.

We believe that 2019 will a vibrant, protective and creative year for those committed to integrated research and we expect JPHI to be the portal that keeps you abreast of cutting edge information in Pharmaceutical Sciences. 